\title{
Phase Analysis of Materials for Steam and Gas Turbines
}

\author{
Pigrova G.D.
}

Central Boiler and Turbine Institute, St.Petersburg, Russia

The necessity for receiving phase time-temperature diagrams of high-alloyed materials and alloying elements redistribution between phases is associated with the choosing of optimal thermal treatment conditions, providing phase stability for steels and alloys during operation. The present paper deals with investigations of phase diagrams for high-temperature Ni-base alloy and for $\mathrm{Cr}-\mathrm{Mo}-\mathrm{V}$ steel have been received. The type of phase transformations (carbide, boride and intermetallic) has been determined during long-term ageing.

Experimental. The study was performed by a method of physical-chemical phase analysis. In order to isolate phases from a metal matrix, an electrochemical method using the methanol solution of $\mathrm{HCl}$ cooled to $-3^{0} \mathrm{C}$ was employed. Phase structure were determined by X-ray structure analysis using Co radiation. Temperature-time diagrams are obtained from $\mathrm{X}$-ray analysis results. This article presents data for steel $0.25 \mathrm{C}-1.6 \mathrm{Cr}-1.0 \mathrm{Mo}-0.3 \mathrm{~V}$, study of carbide formation during martensite aging has been carried out at temperatures between $4500^{\circ} \mathrm{C}$ and $750^{\circ} \mathrm{C}$ for times up to 3000 to 5000 hours. The composition of Ni-base alloy melting $(17.7 \% \mathrm{Cr} ; 5.3 \%$ Co, 5.3\% Mo, 3.3\%W, 3.8\% Al, 2.3\% Ti, 1.4\% Nb, 0.10\% C, 0.15\% Si, 0.04\% B) was studied during aging in temperature region of $750-1100^{\circ} \mathrm{C}$ after homogenization at $1180^{\circ} \mathrm{C}$.

Cr-Mo-V steel. The diagrams show the regions of carbide phase existence during metal aging in the martensite state (Fig. 1). The following carbides are found to be present: V-based carbide of MC-type, Mo-rich $\mathrm{M}_{2} \mathrm{C}$ carbides, and $\mathrm{Cr}$ - and Fe-rich $\mathrm{M}_{3} \mathrm{C}, \mathrm{M}_{7} \mathrm{C}_{3}$, and $\mathrm{M}_{23} \mathrm{C}_{6}$ carbides. The dotted line in steel diagram indicates the existence of boundaries of $\mathrm{M}_{3} \mathrm{C}$ cementite. The increase in relative amounts of $\mathrm{M}_{23} \mathrm{C}_{6}$ carbides in the high-temperature metal component is associated with carbide formation during service; moreover, $\mathrm{M}_{23} \mathrm{C}_{6}$ carbide is the major carbide phase in some cases, and this state cannot be achieved during heat treatment. $\mathrm{M}_{3} \mathrm{C}$ cementite decomposes during metal service. Generally, carbide reactions in steel proceed as follows:

$\mathrm{M}_{3} \mathrm{C} \quad \mathrm{MC}+\mathrm{M}_{2} \mathrm{C}+\mathrm{M}_{7} \mathrm{C}_{3} \quad \mathrm{M}_{23} \mathrm{C}_{6} \quad \mathrm{M}_{6} \mathrm{C}$. Fig. 2 shows changes in alloying elements amounts in carbide phases with aging temperatures. The amounts of $\mathrm{Mo}, \mathrm{Cr}$ and $\mathrm{V}$ present in carbides are found to increase with longer aging times.

Ni-base alloy. High-temperature alloys of this type are multiphase and exhibit the occurrence of several types of different phases: $\mathrm{Ni}_{3} \mathrm{Al}$-base -phase, carbide phases of the $\mathrm{MC}, \mathrm{M}_{23} \mathrm{C}_{6}$ and $\mathrm{M}_{6} \mathrm{C}$ type, TCP(topologically closed packed)-phases of - or -phases, and boride phases. The $\mathrm{Cr}$ base $\mathrm{M}_{23} \mathrm{C}_{6}$ carbide forms during subsequent tempering at temperature below $1000^{\circ} \mathrm{C}$. In order to determine time-temperature ranges of -phase existence in the alloy, a phase diagram for temperature ranging from $750-1100^{\circ} \mathrm{C}$ has been built (Fig.3). The -phase formation at $800^{\circ} \mathrm{C}$ has been found after aging during 500 hours, the quantity of $\mathrm{Cr}$ and $\mathrm{Mo}$ bound in the second phases is growing substantially (Fig.4). - phase forms more vigorously at $900^{\circ} \mathrm{C}$ and is found to occur after 50 hours of aging. -phase is instable at temperatures over $950^{\circ} \mathrm{C}$. Generally, the main phase reactions during long-term aging are carbide reaction $\mathrm{MC} \quad \mathrm{M}_{23} \mathrm{C}_{6}$ and - phase formation.. At $800^{\circ} \mathrm{C}$ the -phase precipitation is initiated at the aging time interval of 500-1000 hours, while at $900^{\circ} \mathrm{C}$ the onset of -phase precipitation falls within 30-50 hours. 


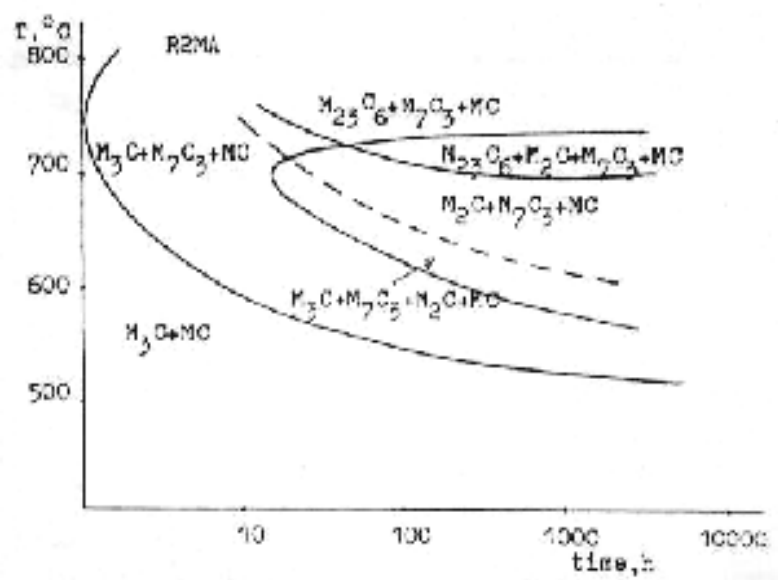

Fig. 1 Time- temperature carbide diagram for steel

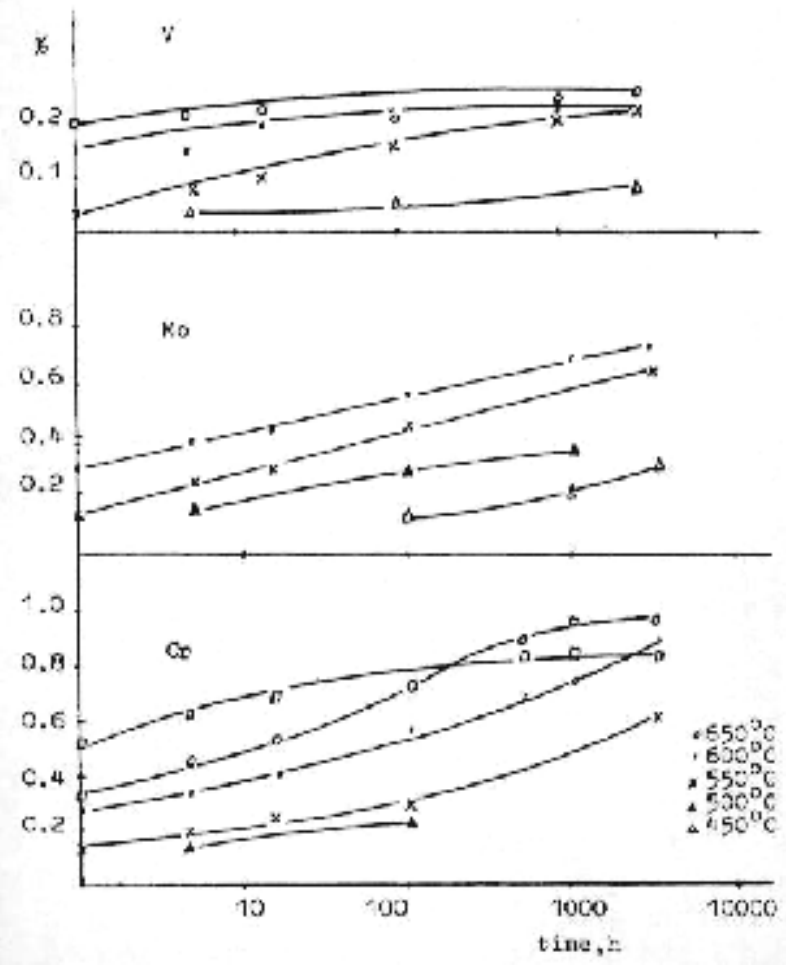

Fig. 2 Vanadium, molybdenum and chromium content in carbides during steel aging

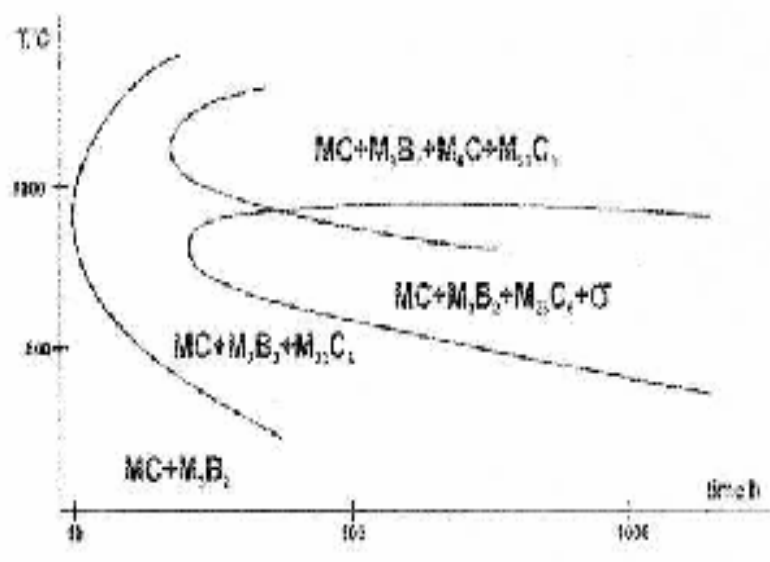

Fig. 3 Time- temperature phase diagram for Ni-base alloy.
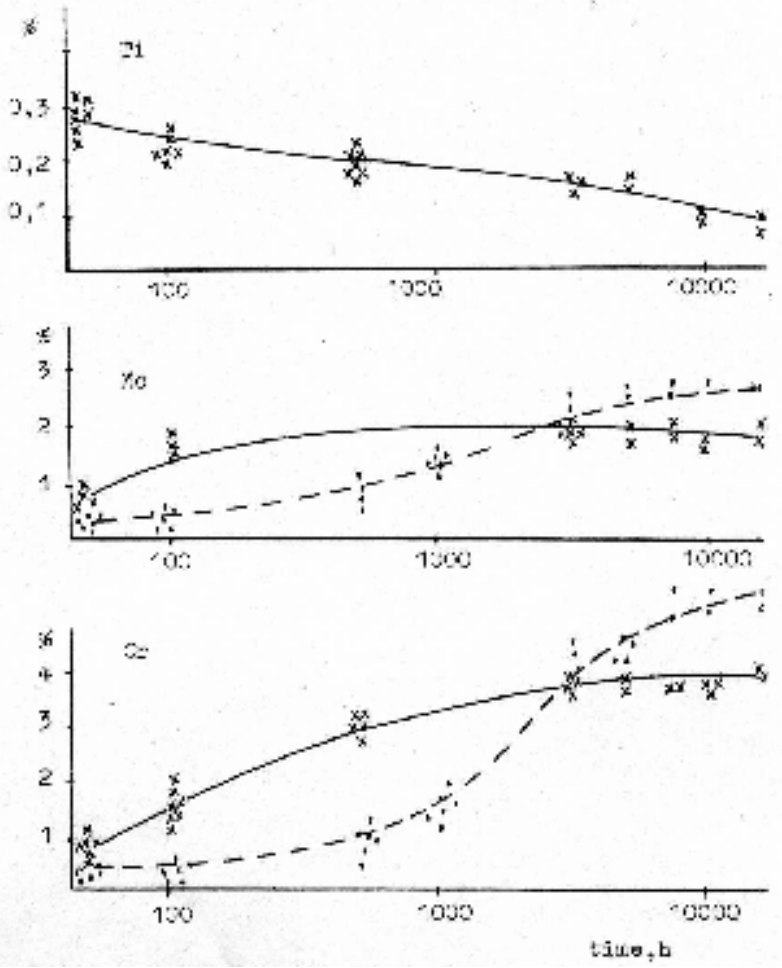

Fig. 4 Titanium, molybdenum and chromium content in second phases during aging at $800(----)$ and $900^{\circ} \mathrm{C}(---)$ 